\title{
Accuracy of Heart Auscultation Examination by General Practitioners From Various Levels of Competency in Detection of Heart Abnormality in Basic School Children
}

\author{
Annisa Permatasari ${ }^{1}$, Deny Salverra Yosy ${ }^{1}$, Achirul Bakri $^{1}$, Ria Nova $^{1^{*}}$
}

${ }^{1}$ Department of Pediatric, Faculty of Medicine, Universitas Sriwijaya/Dr. Mohammad Hoesin General Hospital, Palembang, Indonesia

\author{
A R T I C L E I N F O \\ Keywords: \\ Auscultation \\ Heart defects \\ Elementary school children \\ *Corresponding author: \\ Ria Nova \\ E-mail address: \\ rialuthfan@yahoo.com
}

All authors have reviewed and approved the final version of the manuscript.

https://doi.org/10.37275/bsm.v6i3.460

\begin{abstract}
A B S T R A C T
Background: Most of heart defects in children do not show typical clinical symptoms. Ten percent of the cases are late detected. Echocardiography is an examination with high sensitivity and specificity in detecting heart defects in children, but it cannot be performed by all health workers, expensive and not always available in hospitals. Auscultation is an important part of a physical examination that inexpensive, easy examination, and becomes a competency of all doctors. The aim of this study to determine the accuracy of the screening method by listening to murmurs on heart auscultation by various levels of physician competence.

Methods: This is a diagnostic test of 250 elementary school children held in the pediatric ward of dr. Mohammad Hoesin Palembang from September to November 2019. The auscultation examination was performed by three pediatrics resident from three stages (i.e. junior, middle and senior), followed by echocardiography examinations by a pediatric cardiologist.

Results: The highest sensitivity of auscultation was found in senior resident, $42.4 \%$, while the lowest was found in junior resident, $12.1 \%$. The results of the kappa analysis of the cardiac auscultation examination on the three examiners showed a poor level of agreement on junior stage compared to senior resident $(\mathrm{k}$ $=0.189 ; \mathrm{CI}=0.033-0.346)$ and the level of agreement was sufficient in junior stage compared to middle stage resident $(\mathrm{k}=0.297 ; \mathrm{CI}=0.134-0.461)$ and middle stage compared to senior resident $(\mathrm{k}=0.301 ; \mathrm{CI}=0.147-0.456)$.

Conclusion: Experience and length of learning will affect the accuracy of the auscultation examination in detecting heart defects in children.
\end{abstract}

\section{Introduction}

Heart defects in children can be either congenital or acquired. The clinical symptoms of heart defects in children vary depending on the type of lesion. The incidence and prevalence of congenital heart defects in children varies. In Asia, it is estimated that 9.3 / 1000 live births, in Europe 8.2 / 1000 live births and North America 6.9 / 1000 live births. One of the heart defects in children that do not cause clinical symptoms is subclinical rheumatic heart disease (RHD). The prevalence study by Saxena et al in 2011 showed the prevalence of subclinical RHD among primary school children aged 5-11 years in India was 20.4 per 1000 children. ${ }^{1-3}$

The high prevalence of heart defects in children requires early detection for disease management. Currently, there is no guideline of heart defects screening in children. Echocardiography is an examination that has high sensitivity and specificity in 
detecting heart abnormalities in children, however, echocardiography is not always available in hospitals and expensive, so it cannot be used as a tool for screening heart defects in children. ${ }^{4-6}$

Auscultation is an important part of a physical examination of the heart and the competence of all doctors, both general practitioners, pediatric residents, and pediatricians. Complete heart physical examination such as auscultation examination listening to heart sounds and murmurs can be used as a tool to screen for heart defects in children. ${ }^{7-9}$

Several studies have shown the accuracy of cardiac auscultation diagnosis varies from 20 to $84 \%$. Kumar et al (2013) conducted a study on the evaluation of cardiac auscultation examinations by pediatric resident using a computer heart sound application, obtained a sensitivity of $82 \%$ and a specificity of $56 \%$ with an accuracy of $73 \%$. Dhuper et al (2015) conducted a study on the evaluation of cardiac auscultation in pediatric residents from various stages of competence to diagnose heart defects. In that study, it was found that the accuracy was higher in pediatric residents that had passed cardiology rotation than those that had not (41\% vs $18 \%$ ), with the highest accuracy reaching $84 \%$ in the identification of innocent murmurs. ${ }^{4,7-9}$

Uner et al (2008) conducted a heart auscultation examination in 6035 children aged 6-15 years. Murmurs of varying intensity were obtained in 243 (4\%) patients. A total of 209 (3.5\%) children had innocent murmur without any abnormalities, 27 (0.4\%) children had congenital heart disease and $7(0.1 \%)$ children had rheumatic heart disease. ${ }^{6}$

Not all heart defects will cause a pathological murmur on auscultation of the heart. In contrast, murmurs can be found in 50\% of healthy children, which most of them are innocent murmurs and not dangerous. Innocent murmur is the normal pattern of blood flow through the heart and blood vessels. Perhaps only a portion of the heart defects will be detected on screening by cardiac auscultation, but this method is currently better than other screening methods such as echocardiography which are difficult to perform. ${ }^{7,10-13}$ This study aims to determine the accuracy of the screening method by listening to heart murmurs by various competency levels of doctors in the detection of heart defects in children in Palembang City.

\section{Methods}

This study is a diagnostic test with cross sectional approach of 250 elementary school children from 5 subdistricts in Palembang. The research took place from September 2019 to November 2019. The selection of the research sample was carried out by cluster random sampling. The inclusion criteria were primary school children aged 5-15 years and received consent from their parents to be included in the study by signing the consent form, while the exclusion criteria were children who had already diagnosed with congenital or acquired heart defects.

Research subjects and parents were given explanation of the research and asked for parental consent. Research subjects were picked up from their respective schools to the pediatric ward at $\mathrm{Dr}$. Mohammad Hoesin Hospital to do anamnesis, physical examination and echocardiography. Anamnesis includes identification of name, age and gender. Anthopometric status were obtained by body weight and height measurement. The auscultation examination was carried out by 3 pediatric residents from 3 stages (i.e. junior, middle and senior), who were selected randomly, in the diagnostic room of the children's ward at dr. Mohammad Hoesin Palembang.

The junior resident is resident that has passed 1 month learning stage in the cardiology division, the middle resident is resident which has gone through 2 months of learning stage in the cardiology division and the senior resident is resident that has passed 3 months of learning stage in the cardiology division. The three examiners auscultated all subjects to identify heart sounds and murmurs which were divided into physiological murmurs and pathological murmurs, using a classic II pediatric littmann stethoscope separately in a quiet closed room and did not know the other resident's results of the auscultation.

One pediatric cardiac consultant performed echocardiography using a machine echocardiography 
with Philips brand HD7 XE type, without knowing the results of auscultation. The examination was carried out on Saturdays and Sundays with a total of 20 children per day. This research was approved by the Ethics Committee of Dr. Mohammad Hoesin Hospital and the school that was selected as the research sample.

Data were recorded on a research form, then entered into a computer using the SPSS Version 16.0 program. Furthermore, the data obtained will be processed by tabulating and displayed in tables. The diagnostic test results are expressed in a $2 \times 2$ table, then the sensitivity, specificity, accuracy, positive predictive value and negative predictive value are calculated. Kappa analysis was performed to see the suitability of the cardiac auscultation examination among the three examiners.

\section{Results}

There were 250 elementary school students who were become the research subjects. Age varies with the age range 5-14 years old. The largest age range is in the range 5 - 10 years old (63.4\%) with a median age of 9.4 years. Most of the sexes are women, 135 (52.8\%). Most nutritional status was good nutrition in 132 research subjects (52.8\%) followed by under nutrition as much as $30 \%$. General characteristics of research subjects can be seen in Table 1 .

Table 1. Demographic characteristics of sample

\begin{tabular}{|l|l|}
\hline \multicolumn{1}{|c|}{ Variable } & \multicolumn{1}{|c|}{ Total } \\
\hline Age, n (\%) & $5-14(100)$ \\
\hline$-\quad$ Range, years & $156(63.4)$ \\
\hline$-\quad$ 5-10 years 10 years & $94(37.6)$ \\
\hline$-\quad$ Male & $118(47.2)$ \\
\hline$-\quad$ Female & $132(52.8)$ \\
\hline$-\quad$ Poor nutrition & $75(30)$ \\
\hline$-\quad$ Good nutrition & $132(52.8)$ \\
\hline$-\quad$ Over nutrition & $30(12)$ \\
\hline$-\quad$ Obesity & $13(5.2)$ \\
\hline
\end{tabular}

Junior resident found murmurs in 24 (9.6\%) of the study subjects, while middle stage and senior resident found murmurs in 39 (15.6\%) of the study subjects. In the study subjects who had a murmur, the three examiners distinguished physiological murmurs and pathological murmurs. Of the study subjects who had murmurs, the junior resident found physiological murmurs in $18(75 \%)$ of the study subjects, while middle stage resident found physiological murmurs in $28(71.7 \%)$ of the study subjects and the senior resident found physiological murmurs in 23 (58.9\%) research subject.

The most common degree of murmur was grade III/ 6 in $97.4 \%$ of study subjects followed by grade II/ 6 in 1 study subject. Auscultation studies include abnormal heart sounds, presence or absence of murmurs, type of murmur, phase of the murmur and degree of murmur (Table 2). 
Table 2. Characteristics of murmurs on auscultation examination in research subjects

\begin{tabular}{|c|c|c|c|}
\hline Variable & Junior resident & Middle resident & Senior resident \\
\hline \multicolumn{4}{|l|}{ Murmur, n (\%) } \\
\hline - $\quad$ Murmur & $24(9.6)$ & $39(15.6)$ & $39(15.6)$ \\
\hline - $\quad$ No murmur & $226(90.4)$ & $211(84.4)$ & $211(84.4)$ \\
\hline \multicolumn{4}{|l|}{ Type of murmur, n (\%) } \\
\hline - $\quad$ Physiological murmur & $18(75)$ & $28(71.7)$ & $23(58.9)$ \\
\hline - $\quad$ Pathological murmur & $6(25)$ & $11(28.3)$ & $16(41.1)$ \\
\hline \multicolumn{4}{|l|}{ Abnormal heart sound, n (\%) } \\
\hline - $\quad$ Systolic murmur & $24(100)$ & $38(97.4)$ & $37(94.8)$ \\
\hline - $\quad$ Diastolic murmur & - & - & $1(2.6)$ \\
\hline - $\quad$ Continuous murmur & - & $1(2.6)$ & - \\
\hline - $\quad$ Wide fixed slpit & - & - & $1(2.6)$ \\
\hline \multicolumn{4}{|l|}{ Degree of murmur, n (\%) } \\
\hline$-\quad$ II / 6 & $3(12.5)$ & $3(7.6)$ & 1 (2.6) \\
\hline$-\quad$ III / 6 & $21(87.5)$ & $35(89.7)$ & $38(97.4)$ \\
\hline$-\quad I V / 6$ & - & $1(2.7)$ & - \\
\hline
\end{tabular}

Auscultation examination of the three examiners was carried out by determining the presence or absence of a murmur and then compared with an echocardiographic examination conducted by a pediatric cardiac consultant. Of the 250 study subjects, 217 (86.8\%) study subjects had normal echocardiography results. $20(8 \%)$ study subjects had subclinical rheumatic heart disease, 10 (4\%) study subjects had primary pulmonary hypertension, 2 $(0.8 \%)$ study subjects had pulmonary stenosis and 1 $(0.4 \%)$ study subjects had persistent foramen ovale. On echocardiography examination, it was found that there was involvement of the heart valve which was further diagnosed by subclinical rheumatic heart disease.

On the auscultation examination conducted by junior resident, it was found that 4 study subjects had heart murmurs accompanied by positive echocardiography results indicating heart defects. Middle stage resident found 13 study subjects had heart murmurs accompanied by positive echocardiography results indicating heart defects. Meanwhile, senior resident was found that 13 study subjects had heart murmurs and positive echocardiography results indicating heart abnormalities. The highest sensitivity of auscultation was found in senior resident, $42.4 \%$, while the lowest was found in junior resident, $12.1 \%$. Table 3 shows the sensitivity, specivisity, accuracy, false positive, false negative, positive predictive value (PPV), negative predictive value (NPV), positive likelihood ratio (PLR) and negative likelihood ratio (NLR) that differ at each stage of pediatric residents. 
Table 3. Comparison of the diagnostic test results of murmur examination on heart auscultation with the echocardiography gold standard in the three examiners

\begin{tabular}{|c|c|c|c|}
\hline & Junior resident & Middle resident & Senior resident \\
\hline Sensitivity (\%) (95\% CI) & $\begin{array}{l}12.1 \\
(3.9 \%-29.14 \%)\end{array}$ & $\begin{array}{l}39.3 \\
(23.4 \%-57.7 \%)\end{array}$ & $\begin{array}{l}42.4 \\
(25.9 \%-60.6 \%)\end{array}$ \\
\hline Specificity (\%) (95\% CI) & $\begin{array}{l}90.7 \\
(85.9 \%-94.1 \%)\end{array}$ & $\begin{array}{l}88.0 \\
(82.7 \%-91.8 \%\end{array}$ & $\begin{array}{l}88.4 \\
(83.2 \%-92.2 \%)\end{array}$ \\
\hline Accuracy (\%) & 80.4 & 81.6 & 82.4 \\
\hline False positive $(95 \% \mathrm{CI})$ & $\begin{array}{l}83.3 \% \\
(61.8 \%-94.5 \%)\end{array}$ & $\begin{array}{l}66.6 \% \\
(49.6 \%-80.4 \%\end{array}$ & $\begin{array}{l}64.1 \% \\
(47.1 \%-78.3 \%\end{array}$ \\
\hline False negative $(95 \% \mathrm{CI})$ & $\begin{array}{l}12.83 \% \\
(8.8 \%-18 \%)\end{array}$ & $\begin{array}{l}9.4 \% \\
(6 \%-14.4 \%)\end{array}$ & $\begin{array}{l}9 \% \\
(5.6 \%-13.9 \%)\end{array}$ \\
\hline PPV (\%) $(95 \%$ CI) & $\begin{array}{l}16.6 \\
(5.4 \%-38.1 \%)\end{array}$ & $\begin{array}{l}33 \\
(19.5 \%-50.3 \%\end{array}$ & $\begin{array}{l}25.8 \\
(21.6 \%-52.8 \%)\end{array}$ \\
\hline NPV (\%) (95\% CI) & $\begin{array}{l}87 \\
(81.9 \%-91.1 \%)\end{array}$ & $\begin{array}{l}90.5 \\
(85.5 \%-93.9 \%)\end{array}$ & $\begin{array}{l}90.9 \\
(86 \%-94.3 \%\end{array}$ \\
\hline Positive LR (95\% CI) & $\begin{array}{l}1.31 \\
(0.47-3.6)\end{array}$ & $\begin{array}{l}3.28 \\
(1.88-5.73)\end{array}$ & $\begin{array}{l}3.68 \\
(2.14-6.33)\end{array}$ \\
\hline Negative LR (95\% CI) & $\begin{array}{l}0.96 \\
(0.85-1.09)\end{array}$ & $\begin{array}{l}0.68 \\
(0.52-0.9)\end{array}$ & $\begin{array}{l}0.65 \\
(0.48-0.87)\end{array}$ \\
\hline
\end{tabular}

CI - confidence interval, PPV - positive predictive value, NPV - negative predictive value, LR - Likelihood ratio.

Auscultation of the three examiners also determined physiological and pathological murmurs, which were then compared with echocardiographic examinations. On the auscultation examination performed by junior stage pediatric resident, it was found that 3 study subjects had pathological heart murmurs accompanied by positive echocardiography results indicating heart defects. There was 1 study subject with a physiological heart murmur but a positive echocardiography showed a heart defect.

On the auscultation examination carried out by middle stage resident, 10 study subjects had pathological heart murmurs and positive echocardiography results showed heart abnormalities. There were 3 study subjects with physiological heart murmurs, but positive echocardiography results showed heart abnormalities.

On the auscultation examination performed by senior resident, 13 study subjects had pathological heart murmurs accompanied by positive echocardiography results indicating heart defects. Meanwhile, there was 1 study subject with a physiological heart murmur but positive echocardiography results indicated a heart defect. Table 4 shows the sensitivity, specificity, accuracy, false positive, false negative, positive predictive value (PPV), negative predictive value (NPV), positive likelihood ratio (LR) and negative likelihood ratio (LR) that are different at each stage of the pediatric residents in examination of physiological murmurs and pathological murmurs. 
Table 4. Comparison of diagnostic test results examination of physiological murmurs and pathological murmurs on heart auscultation with echocardiography gold standard in the three examiners

\begin{tabular}{|c|c|c|c|}
\hline & Junior resident & Middle resident & Senior resident \\
\hline Sensitivity (\%) (95\% CI) & $\begin{array}{l}75 \\
(21.9 \%-98.6 \%)\end{array}$ & $\begin{array}{l}76.9 \\
(45.9 \%-93.8 \%)\end{array}$ & $\begin{array}{l}92.8 \\
(64.1 \%-99.6 \%)\end{array}$ \\
\hline Specificity (\%) (95\% CI) & $\begin{array}{l}85 \\
(61.1 \%-96 \%)\end{array}$ & $\begin{array}{l}96.1 \\
(78.4 \%-99.7 \%)\end{array}$ & $\begin{array}{l}88 \\
(67.6 \%-96.8 \%)\end{array}$ \\
\hline Accuracy (\%) & 83 & 89 & 89.7 \\
\hline False positive $(95 \% \mathrm{CI})$ & $\begin{array}{l}50 \\
(13.9 \%-86 \%)\end{array}$ & $\begin{array}{l}9 \% \\
(4.7 \%-42 \%\end{array}$ & $\begin{array}{l}18.7 \% \\
(4.9 \%-46.3 \%\end{array}$ \\
\hline False negative (95\% CI) & $\begin{array}{l}55.5 \\
(2.9 \%-29.3 \%)\end{array}$ & $\begin{array}{l}10.7 \% \\
(2.8 \%-29.3 \%\end{array}$ & $\begin{array}{l}4.3 \% \\
(2.2 \%-23.9 \%)\end{array}$ \\
\hline PPV (\%) (95\% CI) & $\begin{array}{l}50 \\
(13.9 \%-86 \%)\end{array}$ & $\begin{array}{l}90.9 \\
(57.1 \%)-99.5 \%)\end{array}$ & $\begin{array}{l}81.2 \\
(53.6 \%-95 \%)\end{array}$ \\
\hline NPV (\%) (95\% CI) & $\begin{array}{l}94 \\
(70.6 \%-99.7 \%)\end{array}$ & $\begin{array}{l}89.2 \\
(70.6 \%-97.1 \%)\end{array}$ & $\begin{array}{l}95.6 \\
(76 \%-23.9 \%)\end{array}$ \\
\hline Positive LR (95\% CI) & $\begin{array}{l}5 \\
(1.5-16.38)\end{array}$ & $\begin{array}{l}20 \\
(2.8-139.8)\end{array}$ & $\begin{array}{l}7.7 \\
2.6-22.5)\end{array}$ \\
\hline Negative LR (95\% CI) & $\begin{array}{l}0.29 \\
(0.05-1.6)\end{array}$ & $\begin{array}{l}0.24 \\
(0.08-0.64)\end{array}$ & $\begin{array}{l}0.08 \\
(0.01-0.54)\end{array}$ \\
\hline
\end{tabular}

CI - confidence interval, PPV - positive predictive value, NPV - negative predictive value, LR - Likelihood ratio.

The results of the kappa analysis of the cardiac auscultation examination on the three examiners showed a poor level of agreement on junior resident compared to senior stage pediatric resident $(\mathrm{k}=0.189$; $\mathrm{CI}=0.033-0.346)$ and the level of agreement was sufficient in junior stage pediatric resident compared to middle stage pediatric resident $(\mathrm{k}=0.297 ; \mathrm{CI}=0.134$ 0.461 ) and middle stage pediatric resident compared to seniors stage $(\mathrm{k}=0.301 ; \mathrm{CI}=0.147-0.456)$.

\section{Discussion}

In this study, the age group of elementary school children was 5-14 years old, with the largest range being 5-10 years old. Most of the sexes are women, namely 135 (52.8\%). In Japan, screening for heart defects is routinely carried out in the first year of primary and junior high school. This study is similar to a study by Yilgwan et al (2014) who conducted clinical screening of 408 primary school children in Nigeria with the study subjects who were also dominant 6-12 years with a mean $(9.0 \pm 1.95)$ years and the majority of women as much as 55.5\%.10,14

In this study, pediatric resident in junior stages found murmurs in 24 study subjects (9.6\%), while pediatric resident for Middle and Senior stages found murmurs in 39 study subjects respectively (15.6\%). The number of study subjects who had murmurs in this study was more than the previous studies. The study of Uner et al (2009) aimed to find the significance of clinical evaluation of physiological murmurs and pathological murmurs in detecting heart defects in 6035 school children aged 6 to 15 years. The results of the auscultation examination revealed a murmur in 243 children (4\%) of which 34 (0.55\%) had pathological murmurs. Research by Kang et al (2015), on the prevalence and significance of heart murmurs in the detection of heart defects in 81,213 elementary school children in Dongguan, China. Cardiologist performed a heart murmur and found a murmur in 2193 children $(2.7 \%)$. Based on some literature, the prevalence of heart murmurs in children varies from $6 \%$ to $80 \% .15,16$ 
On the auscultation examination of study subjects, Junior resident found physiological murmurs in 18 study subjects (75\%), while Middle stage resident found physiological murmurs in 28 study subjects $(71.7 \%)$ and Senior resident found physiological murmurs in 23 study subjects (58.9\%). The study of Dhuper et al (2007), showed differences in the results of auscultation at various stages of pediatric resident, the first year pediatric resident detected $14 \%$ of the study sample as having physiological murmurs, the second year pediatric resident detected $43 \%$ physiological murmurs and the third year pediatric resident detected $86 \%$ physiological murmurs in the study sample, there was a significant difference between the three stages of the resident in detecting physiological murmurs with $\mathrm{p}$ value $<0.001 .4$

On examination of the phase and degree of the murmur, a systolic murmur with a grade III/ 6 murmur was mostly found in all three examiners. In contrast to this study, the study of Uner et al (2009), in 6035 elementary school children aged 6-15 years in Turkey, the intensity of heart murmurs found the most was I/ 6 (62\%) followed by II / 6 (37.5\%) and III/ 6 (0.5\%). Kang et al (2015) research on 81,213 elementary school children found murmurs of grade I-II in $81.9 \%$ of children and degrees III-VI in $18.1 \% .15,16$

Out of 250 study subjects, 33 study subjects $(13.2 \%)$ with echocardiography showed heart abnormalities consisting of 20 study subjects (8\%) having subclinical rheumatic heart disease, 10 study subjects (4\%) having primary pulmonary hypertension, 2 study subjects $(0.8 \%)$ had pulmonary stenosis and 1 study subject $(0.4 \%)$ had persistent foramen ovale. In the study of Yilgwan et al (2014), in 418 primary school children aged 6-12 years in Nigeria, the prevalence of congenital heart disease was $0.72 \%$. In the study of Uner et al (2009), the prevalence of congenital heart disease was $0.27 \%$ and acquired heart disease, namely rheumatic heart disease, was 0.3\%. Another study conducted by Saxena et al (2010) in India showed the prevalence of rheumatic heart disease in school children aged 5-15 years was $2.04 \%$. In several other studies, the prevalence of congenital heart disease detected in school-age children was $0.27 \%-0.51 \%$ and the prevalence of acquired heart disease, namely rheumatic heart disease, was 0.03-0.71\%.2,9-11,15

On auscultation examination to determine the presence or absence of heart murmurs which were then compared with echocardiographic examinations, the highest accuracy was obtained in Senior stage pediatric resident, namely $82.4 \%$, followed by Middle stage of pediatric resident, namely $81.6 \%$ and Junior stage pediatric resident, namely $80.4 \%$. A study by Dhuper et al (2007) regarding the accuracy of auscultation examinations in pediatric residents in New York, found an accuracy of $19 \%$ for stage I residents, $21 \%$ for stage 2 residents, and $50 \%$ for stage 3 residents.In this study, the examiner determined a clinical diagnosis based on the results of the auscultation. There are significant differences in accuracy at the three stages, where the resident in stage 3 has the highest accuracy. 4

The results showed that the highest sensitivity to auscultation was in the senior stage pediatric resident, $42 \%$ and the lowest sensitivity in the junior stage pediatric resident, $12 \%$, while the specificity was $88 \%$ $90.7 \%$. The positive predictive values ranged from $16 \%$ $-25.8 \%$ and the negative predictive values ranged from $87 \%-90.9 \%$. Research by Godown et al (2015), showed that auscultation examinations performed by general practitioners had a lower sensitivity compared to echocardiography in detecting rheumatic heart disease (22.2\% vs $97.8 \%)$. A study by Feyza et al (2000), showed that the sensitivity of auscultation examination by pediatricians was $63.8 \%$ and by pediatric cardiologists was $95.7 \%$ with a specificity of $99.7 \%$. Research by Sackey et al (2016), in 230 children referred to the polyclinic showed that the results of auscultation by a pediatrician had a sensitivity of $93 \%$, a specificity of $59 \%$, a positive predictive value of $35 \%$ and a negative predictive value of $97 \%$ in diagnosing congenital heart defects in children. $6,11,13$

The study of Haney et al (1999) showed that the sensitivity and specificity of cardiac auscultation examination in pediatricians were $82 \%$ and $24 \%$, which with training in the recognition of pediatric heart sounds increased to $87 \%$ and $98 \%$, respectively. ${ }^{17}$

On auscultation examination to determine physiological murmurs and pathological murmurs, the 
highest sensitivity value was found in Senior stage pediatric resident, namely 92\%, while the highest specificity was found in Middle stage pediatric resident, namely $96 \%$. The highest accuracy was obtained in Senior stage pediatric resident, namely $89.7 \%$, followed by Middle stage pediatric resident at $89 \%$ and Junior stage pediatric resident, namely $83 \%$. The highest positive likelihood ratio (LR) was found in Middle stage pediatric resident, namely 20 and the closest negative probability ratio (LR) to 0 was found in Senior stage pediatric resident, namely 0.08 .

The results of the study were not much different from the study of Dhuper et al. (2007) regarding the accuracy of auscultation examinations in pediatric residents in New York. It was found that the accuracy reached $80 \%$ in stage 3 residents in distinguishing physiological murmurs and pathological murmurs. The high accuracy results were also presented in the study of Solang et al. (2006) in the RSCM general pediatric clinic regarding clinical acuity in diagnosing innocene noise, showing sensitivity and specificity of $97 \%$ and $50 \%$. The positive predictive value is $91 \%$ and the negative predictive value is $75 \%$. The likelihood ratio for a positive result is 1.94 and a negative result is 0.6 . This suggests that physiological murmurs are common in healthy children and can be diagnosed accurately by auscultation. 4,18 These results indicate that physiological murmurs are common in healthy children and can be detected accurately by auscultation.

The reliability test in this study showed that the level of agreement was poor in the junior stage pediatric resident compared to the senior stage pediatric resident $(\mathrm{k}=0.189 ; \mathrm{CI}=0.033-0.346)$ and the level of agreement was sufficient in the junior stage pediatric resident compared to middle stage $(\mathrm{k}=0.297 ; \mathrm{CI}=0.134-0.461)$ ) and middle stage pediatric resident compared to seniors stage $(\mathrm{k}=0.301 ; \mathrm{CI}=0.147-0.456)$. This result is different from the study of Discigil et al. (2010), there was good consistency in cardiac auscultation examinations between family doctors and pediatric cardiac consultants $(\mathrm{k}=0.679$, 95\% CI $0.63 \%-72.7 \%$, $\mathrm{p}<0.001)$ where there was a high agreement in determining innocent murmurs and normal examination results. 19
In this study, the types of heart defects that were not detected through cardiac auscultation were subclinical rheumatic heart disease (17 cases were undetected in junior stage pediatric resident, 12 cases in middle and senior stage pediatric resident), primary pulmonary hypertension (10 cases were not detected in junior stage pediatric resident, 6 cases in middle and senior stage pediatric resident), pulmonary stenosis (1 case undetected in all three examiners) and PFO (1 case undetected in junior and middle stage pediatric resident).

There are several factors that influence the differences in the results of the auscultation, i.e. (1) examiner factors, in this study it is proven that experience affects the results of the accuracy of the cardiac auscultation examination, (2) patient factors, the research subjects are elementary school children with a high level of activity, where at conditions after activity also influenced the sound of murmurs in research subjects, (3) environmental factors, researchers tried to minimize bias by facilitating the examination site which was quiet and far from noise, but there were some times when there was still noise in the lively building on 1st floor because the examination site was close to patient ward and waiting room, (4) heart defects, in this study, there were several heart defects that could not cause murmurs. In subclinical rheumatic heart disease with little heart valve involvement, the murmur is often not be heard. In congenital heart defects with small defects such as PFO can also not be heard on a heart murmur.

Based on this study, it was found that the cardiac auscultation examination on the three examiners had a fairly high specificity but moderate sensitivity. A good screening test is one with high sensitivity and specificity but most of the screening tests do not have this capability. In a diagnostic test that is aimed at a screening program, in order for the program to run effectively, it is expected that the screening test chosen is a test with high sensitivity even though the specificity is not too high.

In this study, the sensitivity of junior stage pediatric resident was not too high, namely $12.1 \%$, but because auscultation is a non-invasive, practical, easy, 
inexpensive and simple examination, while there is no other screening tool that can replace auscultation, auscultation can still be used as a screening tool. However, be careful that there are still many cases of heart defects that can't be detected from the auscultation of the heart.

\section{Conclusion}

This study showed the higher the competency stage, the higher the accuracy and sensitivity of the cardiac auscultation examination. This shows that the factors of experience and length of learning will affect the accuracy of the auscultation examination in detecting heart defects in children.

\section{References}

1. Wanni KA, Shahzad N, Ashraf M, Ahmed K, Jan M, Rasool S. Prevalence and spectrum of congenital heart diseases in children. Heart India. 2014; 2: 76-8. DOI: 10.4103/2321449x. 140230.

2. Saxena A, Ramakrishnan S, Roy A, Seth S, Krishnan A, Misra P, et al. Prevalence and outcome of subclinical rheumatic heart diseases in india: The RHEUMATIC (Rheumatic Heart Echo Utilisation and Monitoring Actuarial Trends in Indian Children) study. Heart. 2011; 9: 2018-22. DOI: 10.1136/heartjnl-2011-300792.

3. Liberman RF, Getz KD, Lin AE, Higgins CA, Sekhavat S, Markenson GR, et al. Delayed diagnosis of critical congenital heart defects: Trends and Associated Factors. Pediatrics. 2014; 134: 373-81. DOI: 10.1542/peds.20133949.

4. Dhuper $\mathrm{S}$, et al. Improvement of cardiac auscultation skills in pediatric residents with training. Clin Ped. 2007; 46: 236-9. DOI: $\underline{10.1177 / 0009922806290028}$.

5. Patel A, Tomar NS, Bharani A. Utility of physical examination and comparison to echocardiography for cardiac diagnosis. Indian Heart Journal. 2017; 69: 141-5. DOI: 10.1016/i.ihj.2016.07.020.
6. Uner A, Dogan M, Bay A, Gakik C, Kaya A, Sai E. The ratio of congenital heart disease and innocent murmur in children in van city, the Eastern Turkey. Anadolu Kardiyol Derg. 2009; 9: 29-34.

7. Zhao QM, Niu C, Liu F, Wu L, Ma XJ, Huang GY. Accuracy of cardiac auscultation in detection of neonatal congenital heart disease by general paediatricians. Cardiol young. 2018: 20: 1-5. DOI:10.1017/S1047951119000799. DOI: $10.1017 /$ S1047951119000799.

8. Sackey AH. Prevalence and diagnostic accuracy of heart disease in children with asymptomatic murmurs. Cardiol young. 2016; 26: 446-50. DOI: $\underline{10.1017 / \mathrm{S} 1047951115000396 .}$

9. Pac FA, Karabiber H, Kilic A, Kutlu O, Yakinci C, Egri M. Evaluation of cardiac murmurs in 8647 children at primary school-age children in the Province of Malatya, Eastern Turkiye. Paediatr Indones. 2000; 41: 42-6. DOI: https://doi.org/10.14238/pi41.1.2001.42-6.

10. Yilgwan CS, Thomas FD. Clinical screening for heart disease in apparently healthy Nigerian school children. Nig Jour of Car. 2014; 11: 749. DOI: 10.4103/0189-7969.142085.

11. Daham AN, Al-Meshhadani, King N. Cardiac auscultation versus two-dimensional transthoracic echocardiography for detection of valve disease in Erbil City. $J$ Heart and Cardiology. 2017; 3: 7-10. DOI: 10.15436/2378-6914.17.1352.

12. Godown J, Lu JC, Beaton AB, Sable C, Miremble G, Aliku RT. Handheld Echocardiography versus auscultation for detection of rheumatic heart disease. Pediatrics. 2015; 4: 939-33. DOI: 10.1542/peds.2014-2774.

13. Binka EK, Linda O, Lewin, Gaskin PR. Small Steps in Impacting Clinical Auscultation of Medical Students. Glob Pediatr Health. 2016; 3: 1-5. DOI: $10.1177 / 2333794 X 16669013$.

14. Sumitomo N, Baba $R$, Doi $S$, Higaki $T$, Horigome $\mathrm{H}$, Ichida $\mathrm{F}$, et al. Guidelines for Heart Disease Screening in Schools. Circ J. 
2016; 6: 1-5.doi:10.1253/circj.CJ-66-0153.

DOI: https://doi.org/10.1253/circj.CJ-66-

$\underline{0153}$.

15. Carapetis JR, Hardy M, Fakakovikaetau T, Taib R, Wilkinson L, Penny DJ, et al. Evaluation of a screening protocol using auscultation and portable echocardiography to detect asymptomatic rheumatic heart disease in Tongan schoolchild. Nat Clin Pract Card. 2007; 5: 411-7. DOI: 10.1038/ncpcardio1185.

16. Kang G, Xiao J, Wang Y, Wang J, Chen Y, Liu $Q$, et al. Prevalence and significance of cardiac murmurs in school children. Arch Dis Child. 2015; 0: 1-4. DOI: $10.1136 /$ archdischild2014-307819

17. Haney I, Ipp M, Feldman W, McCrindle Bw. Accuracy of clinical assessment of heart murmurs by office based (general practice) paediatricians. Arch Dis Child. 1999; 81: 40912. DOI: $10.1136 /$ adc.81.5.409.

18. Solang AD, Advani N, Boediman I. Ketajaman klinis dalam mendiagnosis bising inosen. Sari Pediatri. 2006; 8: 32-6. DOI: http://dx.doi.org/10.14238/sp8.1.2006.

19. Discigil G, Aydogdu A, Gemalmaz A, Gurel FS, Basak O. Cardiac auscultatory skills of academic family physicians: strength of association with an academic pediatric cardiologist. J Family Med. 2010; 20: 14.doi:10.1155/2010/370731. DOI: $\underline{10.1155 / 2010 / 370731}$. 